\title{
Recozimento da Liga de Alumínio AA 7075 após Laminação a frio

Saul Hissaci de Souza ${ }^{1}$ Angelo Fernando Padilha ${ }^{2}$

\begin{abstract}
Resumo
A liga de alumínio AA 7075 recebida no estado T6 (conformada e envelhecida artificialmente) sofreu tratamento térmico a $300^{\circ} \mathrm{C}$ com o objetivo de causar o engrossamento das partículas de $\mathrm{MgZn}_{2}$, intermetálico responsável pelo endurecimento do material. As amostras foram então deformadas $45 \%$ em redução de espessura por laminação e recozidas isotermicamente a $200^{\circ} \mathrm{C}$ e a $250^{\circ} \mathrm{C}$ por tempos variados para estudar a cinética de amolecimento por meio de medidas de dureza Vickers. Os resultados indicam que a cinética de amolecimento em ambas as temperaturas de recozimento aproxima-se do comportamento previsto pelo modelo Johnson-Mehl-Avrami-Kolmogorov (JMAK) com boa concordância (coeficientes de correlação de 0,9725 e 0,9140 a $200^{\circ} \mathrm{C}$ e a $250^{\circ} \mathrm{C}$, respectivamente), ainda que as micrografias ópticas da amostra recozida a $300^{\circ} \mathrm{C}$ por 4 horas não evidenciem a ocorrência de recristalização.
\end{abstract}

\section{Palavras-chave:}

Liga de alumínio AA 7075; Superenvelhecimento; Laminação a frio; Amolecimento.

\section{Annealing of aluminum alloy AA 7075 after cold rolling}

\begin{abstract}
The aluminum alloy AA 7075-T6 (wrought and artificially aged) was heat treated at $300^{\circ} \mathrm{C}$ in order to cause the coarsening of the intermetallic $\mathrm{MgZn}$ 2 particles, that is, the phase which is responsible for the material hardening. The samples were cold rolled (45\% in thickness reduction) and annealed at $200^{\circ} \mathrm{C}$ and $250^{\circ} \mathrm{C}$ at different time intervals to study the softening kinetics by Vickers hardness measurements. The results point out that the softening kinetics at both annealing temperatures are well described by the Johnson-Mehl-Avrami-Kolmogorov (JMAK) model with good agreement (correlation coefficients of 0.9725 and 0.9140 for $200^{\circ} \mathrm{C}$ and $250^{\circ} \mathrm{C}$, respectively), even though optical micrographs of the sample annealed at $300^{\circ} \mathrm{C}$ for 4 hours didn't show the recrystallization occurrence.
\end{abstract}

Keywords: Aluminium alloy AA 7075; Overaging; Cold rolling; Softening.

1 Engenheiro de Materiais, Pós graduando, Departamento de Engenharia Metalúrgica e de Materiais da Escola Politécnica da Universidade de São Paulo (EPUSP), São Paulo, SP, Brasil.

2 Professor Titular, Departamento de Engenharia Metalúrgica e de Materiais da Escola Politécnica da Universidade de São Paulo (EPUSP), São Paulo, SP, Brasil. 


\section{INTRODUÇÃO}

As ligas de alumínio da série 7xxx possuem aplicações em diversas áreas que requerem elevada relação resistência/peso, como as indústrias aeronáutica, automotiva e de transportes. Após o tratamento térmico de envelhecimento (T6) esta liga apresenta alta resistência mecânica, por volta de $500 \mathrm{MPa}$, todavia sua baixa tenacidade e susceptibilidade à corrosão sob tensão limitam a sua utilização em algumas aplicações. Novos ciclos térmicos têm sido pesquisados nesta liga visando uma combinação mais favorável de resistência mecânica e tenacidade [1,2]. O refino de grão promovido pela recristalização é uma característica microestrutural, em geral, desejada para as ligas de alumínio, pois pode resultar em aumento mútuo de resistência mecânica e tenacidade à fratura para esses materiais [3].

O presente trabalho fez uso de medidas de dureza de amostras da AA 7075 previamente superenvelhecidas a $300^{\circ} \mathrm{C}$, deformadas a frio e recozidas a $200^{\circ} \mathrm{C}$ e a $250^{\circ} \mathrm{C}$ para quantificar a variação do amolecimento com o tempo. As medidas de dureza permitem acompanhar a cinética de amolecimento e, ao lado de outras técnicas complementares de análise microestrutural, permitem identificar os modos e mecanismos de amolecimento, tais como recuperação e recristalização [4-5].

Do ponto de vista tecnológico, o conhecimento acerca da cinética de recristalização da AA 7075 para diferentes condições de processamento (temperatura e tempo de recozimento) pode auxiliar na obtenção de microestruturas desejadas e propriedades ótimas para uma dada aplicação.

\section{MATERIAIS E MÉTODOS}

Os experimentos realizados nesse trabalho podem ser divididos em três etapas: a caracterização inicial das amostras recebidas, tratamento térmico para superenvelhecer a liga e laminação na temperatura ambiente seguida de recozimentos isotérmicos a $200^{\circ} \mathrm{C}$ e a $250^{\circ} \mathrm{C}$.

\subsection{Caracterização das amostras no estado inicial}

Amostras da liga AA 7075 no estado T6 (solubilizada e envelhecida artificialmente) foram recebidas na forma de chapas com espessura de $10 \mathrm{~mm}$. A composição química da liga é apresentada na Tabela 1. A microestrutura do material na condição como recebida foi caracterizada com auxílio de microscopia óptica de luz polarizada, microscopia eletrônica de varredura, microanálise química por meio de espectroscopia de raios $\mathrm{X}$ por dispersão de energia, difração de raios $\mathrm{X}$ e medidas de dureza Vickers.

Tabela 1. Composição química (\% em massa) da liga AA7075 pesquisada neste trabalho.

\begin{tabular}{cccccccccc}
\hline Elemento & $\mathrm{Ti}$ & $\mathrm{Mn}$ & $\mathrm{Si}$ & $\mathrm{Cr}$ & $\mathrm{Fe}$ & $\mathrm{Cu}$ & $\mathrm{Mg}$ & $\mathrm{Zn}$ & $\mathrm{Al}$ \\
$\%$ massa & 0,02 & 0,08 & 0,08 & 0,19 & 0,26 & 1,3 & 2,3 & 5,2 & 90,57 \\
\hline
\end{tabular}

A preparação metalográfica para microscopia óptica com luz polarizada foi realizada no laboratório de metalografia da Companhia Brasileira de Alumínio (CBA) localizada na cidade de Alumínio - SP. As amostras foram inicialmente lixadas com lixas de granulação 220,320, 800 e 1200. Em seguida, foram utilizadas técnicas padrão de polimento mecânico, sendo o polimento final executado com suspensão de sílica coloidal em politriz da marca MINIMET 1000. Por fim, as amostras foram 
anodizadas com solução de $\mathrm{HBF}_{4} 1,8 \%$, utilizando fonte $20 \mathrm{~V}$ e anodo da AA 1050 para revelar a estrutura de grãos.

As amostras destinadas para medição de dureza Vickers, difração de raios $\mathrm{X}$ e microscopia eletrônica de varredura foram preparadas através de lixamento (lixas de granulação 220, 400, 600 e 1200) e polidas com uso de pastas diamantadas de granulometrias $6 \mu \mathrm{m}$, $3 \mu \mathrm{m}$ e $1 \mu \mathrm{m}$. As medidas de dureza Vickers foram tomadas com carga de 300 gramas. Para cada amostra foi tomada a média de 10 pontos medidos. $A$ difração de raios $X$ em superfície polida foi utilizada para identificação das partículas de segunda fase presentes na AA 7075 no estado como recebido (T6) e após superenvelhecimento a $300^{\circ} \mathrm{C}$. A faixa de ângulos utilizada foi $20^{\circ}<2 \theta<120^{\circ}$ com passo angular $0,02^{\circ}$. A radiação monocromática utilizada foi $\mathrm{Cu} \mathrm{K} \alpha 1$.

\subsection{Superenvelhecimento artificial e laminação a frio das amostras}

Antes da laminação a frio, as amostras foram levadas a um forno tipo mufla e tratadas a $300^{\circ} \mathrm{C}$ por 5 horas e resfriadas em água a temperatura ambiente. $\mathrm{O}$ objetivo deste tratamento térmico foi causar engrossamento dos precipitados responsáveis pelo endurecimento do material e o consequente aumento de ductilidade da liga. As amostras tratadas foram submetidas à microscopia eletrônica de varredura e ao ensaio de Dureza Vickers (conforme descrito no item 2.1). Em seguida, as amostras tratadas foram laminadas na temperatura ambiente $\left(27^{\circ} \mathrm{C}\right)$, utilizando laminador duo reversível, até atingirem a redução de $45 \%$ de espessura. As tiras laminadas passaram de $10 \mathrm{~mm}$ para $5,5 \mathrm{~mm}$ de espessura, com 0,5 $\mathrm{mm}$ de redução a cada passe. A dureza Vickers das amostras deformadas também foi medida.

\subsection{Recozimentos das amostras deformadas}

As amostras deformadas conforme descrito no item anterior foram submetidas a recozimentos isócronos de 4 horas em diversas temperaturas em forno tubular horizontal. Essa primeira etapa de recozimento serviu para auxiliar a escolha da faixa de temperaturas utilizadas nos recozimentos seguintes.

Em seguida, as amostras deformadas foram recozidas isotermicamente nas temperaturas de $200^{\circ} \mathrm{C}$ e $250^{\circ} \mathrm{C}$ por tempos variados em um forno tubular horizontal.

\section{RESULTADOS E DISCUSSÃO}

Este tópico será subdividido em dois itens, sendo o primeiro relacionado à caracterização do material na condição como recebido e o segundo aos resultados obtidos após os tratamentos térmicos e mecanotérmicos.

\subsection{Caraterização inicial do material como recebido}

A amostra no estado inicial (T6) apresentou grãos de contornos encurvados e alongados na direção de laminação. A Figura 1 mostra a micrografia da superfície normal a um processo de laminação prévio obtida com microscopia óptica de luz polarizada e aumento de 50 vezes. Na imagem é indicado o sentido de laminação prévia experimentada pela liga. 


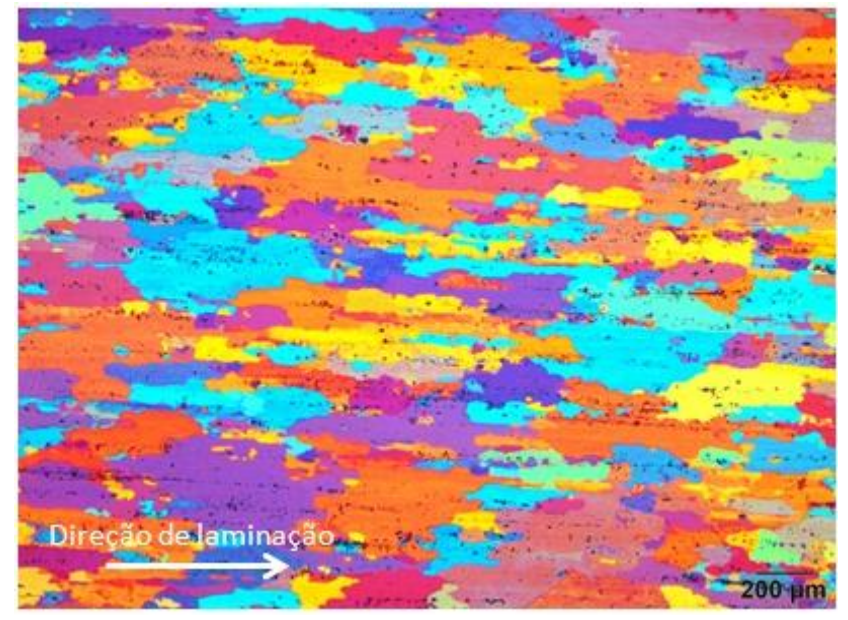

Figura 1 - Micrografia da liga AA 7075 na condição T6 obtida com microscopia óptica de luz polarizada.

A presença dos contornos encurvados na amostra no estado T6 pode ser explicada pela interação destes com os precipitados presentes no material. Tal interação promove o ancoramento dos contornos e dificulta a migração dos mesmos durante alguma etapa anterior de processamento do material em que tenha ocorrido recristalização, ou seja, migração de contornos de alto ângulo. Estruturas similares de grãos também foram observadas em outros trabalhos com a liga AA 7075 - T6 [6-7].

A análise via microscopia eletrônica de varredura indicou a presença de precipitados claros e alinhados, alinhamento este causado por algum um processo prévio de conformação mecânica, provavelmente laminação a quente. A Figura 2 mostra detalhes de um desses precipitados e o respectivo espectro de dispersão de energia (EDS) no lado direito da figura. A análise do precipitado por EDS revelou a presença de um elevado teor de cobre, sendo este um indicativo de que a partícula em questão pudesse ser um intermetálico binário, como $\circ \mathrm{Al}_{2} \mathrm{Cu}$ (fase $\theta$ ) ou talvez um ternário, como $\circ \mathrm{Al}_{(1-2)} \mathrm{CuMg}$ ou ainda $\circ \mathrm{Al}_{7} \mathrm{Cu}_{2} \mathrm{Fe}$, devido à presença significativa de ferro indicada no espectro.
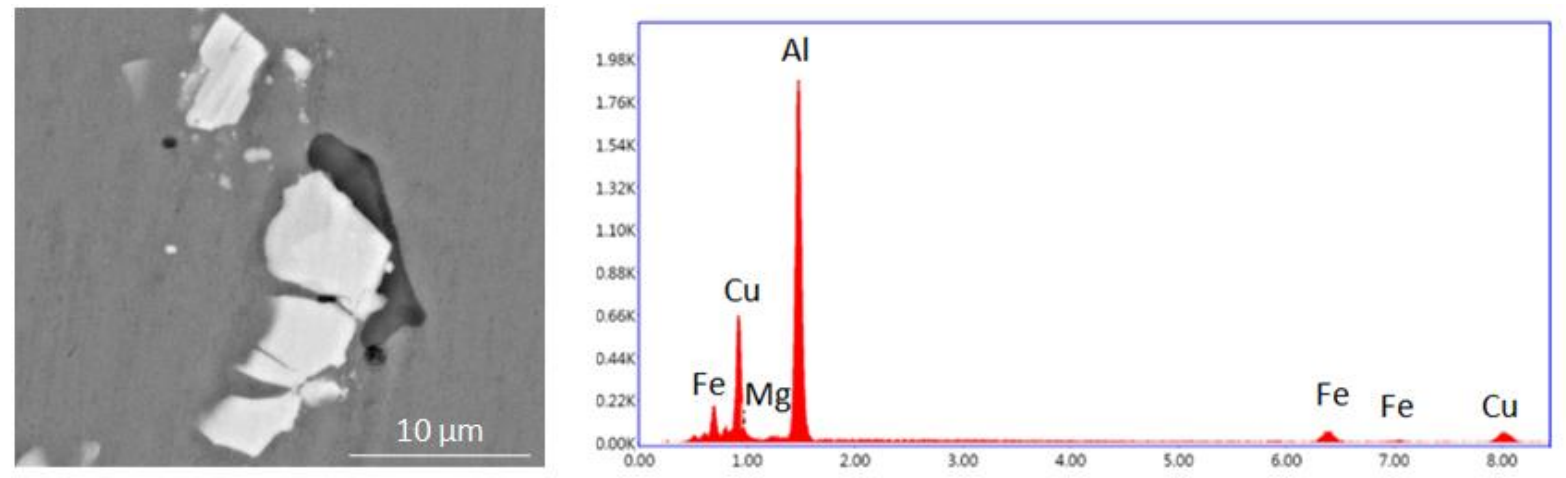

Figura 2 - Imagem com elétrons retroespalhados de precipitados obtida por microscopia eletrônica de varredura e espectro de dispersão de energia realizado do precipitado maior.

A análise por difração de raios $X$ resultou no difratograma exibido na Figura 3 . $O$ asterisco no difratograma indica uma região de picos não identificados. Além dos picos relativos ao alumínio (solução sólida), detectou-se a presença de picos menores, próximos aos ângulos $2 \theta$ de $58^{\circ}$ e $62^{\circ}$. Tais picos ainda não foram identificados, mas acredita-se que estejam relacionados com inclusões insolúveis 
contendo $\mathrm{Fe}$ e $\mathrm{Si}$, tendo em vista que os mesmos foram observados no difratograma das amostras tratadas termicamente.

Embora não encontrada no difratograma da AA 7075 no estado T6, a presença da fase $\mathrm{Al}_{2} \mathrm{CuMg}$ já foi sugerida por Cogan e colaboradores para a liga $A A 7075$ envelhecida em temperaturas elevadas [8]. Outro estudo, realizado por Wert [9], na liga AA 7075 superenvelhecida a $400^{\circ} \mathrm{C}$ apontou que os precipitados presentes são compostos por uma combinação dos intermetálicos $\mathrm{MgZn}_{2}$ e AICuMg, podendo ser representados por $\mathrm{Mg}\left(\mathrm{Zn}_{2}, \mathrm{AlCu}\right)$. É possível que em virtude da baixa fração volumétrica, tais fases não tenham sido detectadas por difração de raios $X$, que, embora precisa, apresenta limite de detecção pobre.

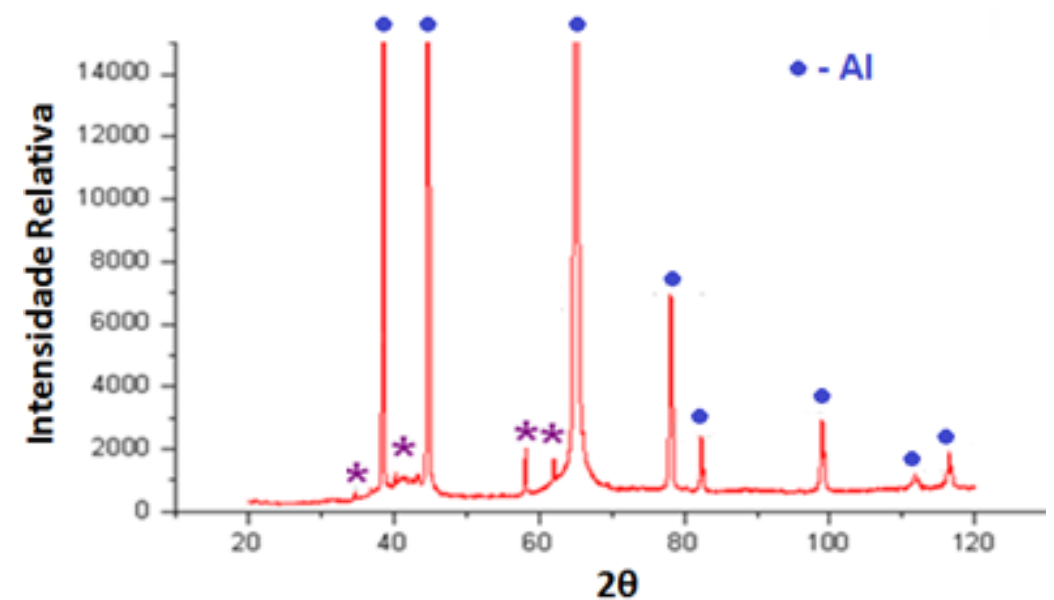

Figura 3 - Difratograma da liga AA 7075 no estado T6. Radiação utilizada: Cu ka1.

\subsection{Tratamentos térmicos e mecanotérmicos}

Após tratamento a $300^{\circ} \mathrm{C}$ por 5 horas, surgiram evidências microestruturais do engrossamento da fase $M g Z n_{2}$ na liga estudada. A Figura 4 mostra micrografia obtida por microscopia eletrônica de varredura, exibindo a presença de pequenas partículas claras, ausentes antes do tratamento térmico de superenvlelhecimento.

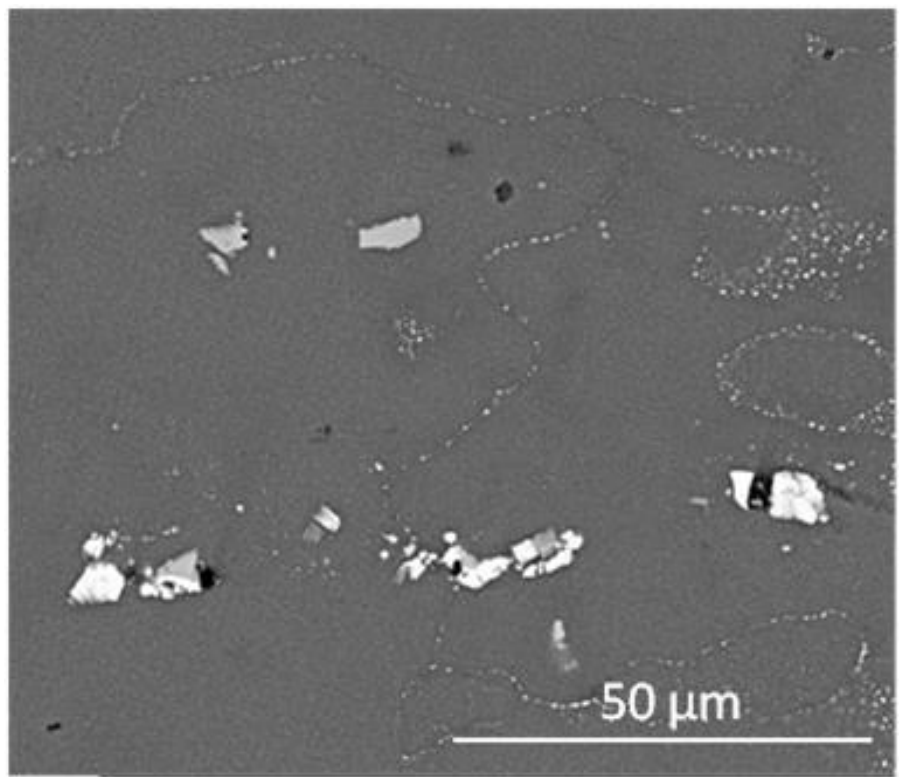

Figura 4 - Micrografia obtida por microscopia eletrônica de varredura (imagem com elétrons

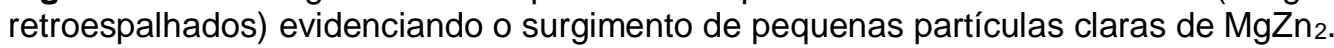


Embora a utilização do EDS para a microanálise dos precipitados finos não fosse viável (as partículas eram muito pequenas; menores que $1 \mu \mathrm{m}$ ), a utilização da difração de raios $X$ apontou a presença de novos picos, possivelmente associados ao $\mathrm{MgZn}_{2}$, sendo que aqueles relativos aos ângulos mais baixos ( $2 \theta$ em torno de $20^{\circ}$ ) são próximos aos indicados na ficha ICSD número 01-077-1177.

Picos mais intensos, presentes na região $40^{\circ}<2 \theta<50^{\circ}$, puderam ser identificados pela ampliação do difratograma na região de interesse. É conhecido que a fase $\mathrm{MgZn}_{2}$ promove o surgimento de picos nessa região, conforme encontrado por outros trabalhos com a AA 7075 [10-11]. Dois picos dessa região foram associados ao AlCuMg, pela proximidade com o pico mais intenso indicado pela ficha ICSD número 03-065-5952. É possível que tais picos estejam sobrepostos àqueles gerados pelo $\mathrm{MgZn}_{2}$, em virtude da proximidade dos ângulos de difração nessa região para essas fases. A Figura 5 mostra 0 difratograma para a liga superenvelhecida a $300^{\circ} \mathrm{C}$.

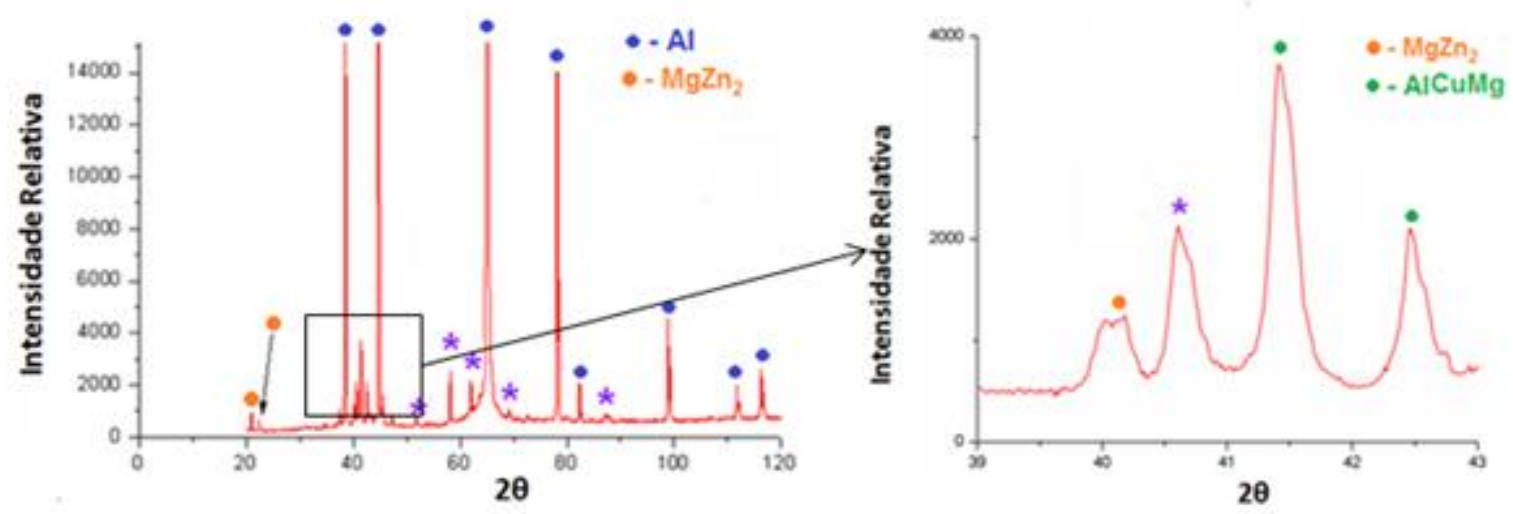

Figura 5 - Difratograma da liga AA 7075 após tratamento de superenvelhecimento a $300^{\circ} \mathrm{C}$. Radiação utilizada: Cu Ka1.

A amostra superenvelhecida a $300^{\circ} \mathrm{C}$ e laminada a frio apresentou grãos com coloração menos definida (Figura 6), em comparação com as imagens obtidas para o estado T6 (compare com a Figura 1). A deformação, além de causar o alongamento dos grãos no sentido da laminação, introduz arranjos de discordâncias no material, que por sua vez acarretam mudanças de orientação no interior de cada grão, causando o efeito mencionado nas cores.

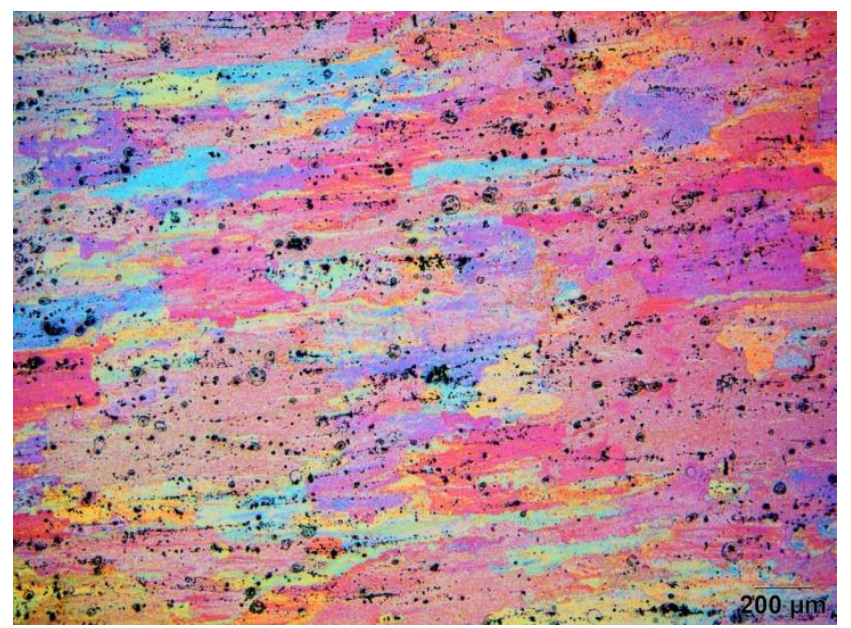

Figura 6 - Micrografia obtida com microscopia óptica de luz polarizada da liga na condição superenvelhecida a $300^{\circ} \mathrm{C}$ e em seguida laminada a frio até $45 \%$ de redução em espessura. 
As amostras laminadas a frio, assim como aquelas utilizadas em etapas anteriores foram submetidas a ensaios de dureza Vickers. A Tabela 2 mostra os resultados de dureza obtidos. Conforme esperado, a dureza da liga diminui após o superenvelhecimento visto que ocorreu o engrossamento de partículas de segunda fase responsáveis por dificultar a movimentação das discordâncias durante a deformação plástica. Por outro lado, a laminação na temperatura ambiente promoveu o aumento da dureza por meio do encruamento do material.

Tabela 2. Medidas de dureza Vickers (carga $300 \mathrm{~g}$ ) das amostras da AA 7075 como recebidas e tratadas.

\begin{tabular}{|lc|}
\hline Tratamentos termomecânicos & $\begin{array}{c}\text { Dureza } \\
\text { Vickers }\end{array}$ \\
\hline T6 (como recebida) & 180 \\
\hline Superenvelhecida $\left(300^{\circ} \mathrm{C}\right.$ por 5 horas) & 82 \\
\hline $\begin{array}{l}\text { Laminada a frio }(45 \% \text { em redução de } \\
\text { espessura) }\end{array}$ & 118 \\
\hline
\end{tabular}

A curva de amolecimento isócrono (4 horas) é exibida na Figura 7. Nota-se que para valores de temperatura menores que $150^{\circ} \mathrm{C}$, o material não apresenta amolecimento apreciável. Por outro lado, temperaturas maiores que $250^{\circ} \mathrm{C}$ resultam em níveis de dureza equivalentes ao do material superenvelhecido. A determinação da curva da Figura 7 facilitou a escolha de temperaturas para os recozimentos isotérmicos.

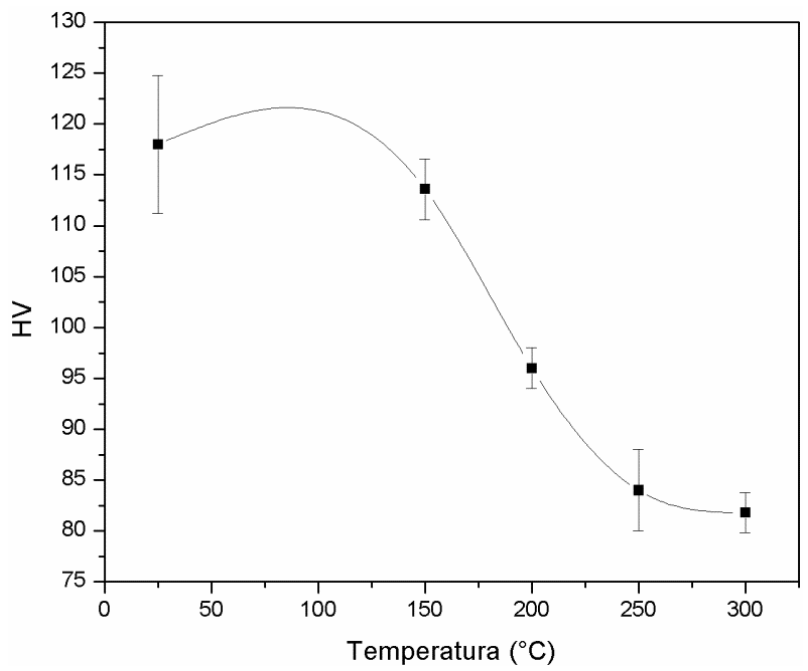

Figura 2 - Curva de amolecimento obtida por recozimentos isócronos com duração de 4 horas.

As curvas de amolecimento obtidas por recozimentos isotérmicos $\left(200^{\circ} \mathrm{C}\right.$ e $\left.250^{\circ} \mathrm{C}\right)$ das amostras são exibidas na Figura 8. Ambas as curvas atingem um patamar para o intervalo estudado, sugerindo que maiores intervalos de tempo de recozimento possivelmente não causariam diminuição significativa da dureza. 


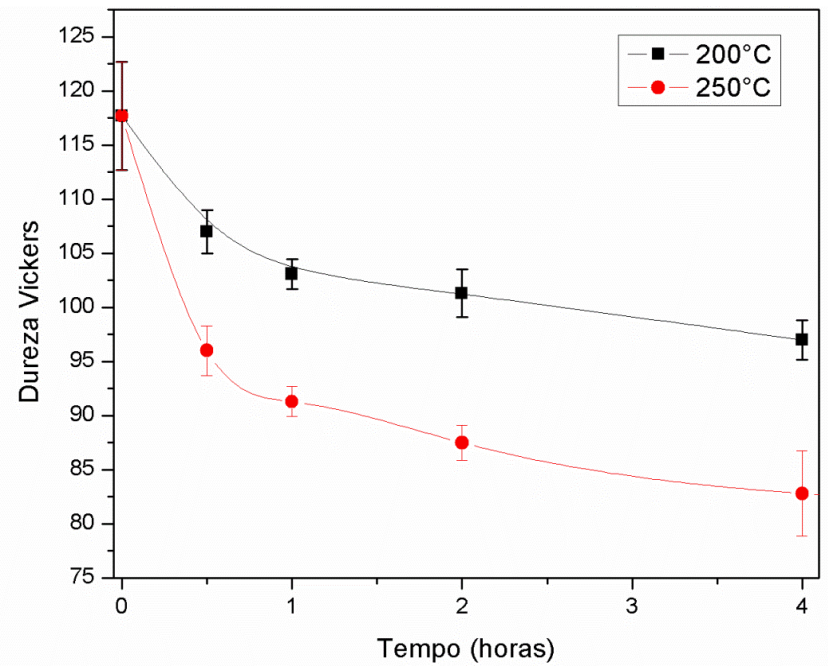

Figura 3 - Curvas de amolecimento obtidas por meio de recozimentos isotérmicos a $200^{\circ} \mathrm{C}$ e $250^{\circ} \mathrm{C}$

Para análise da fração amaciada ou amolecida por meio da variação de dureza, foi utilizada a relação expressa pela Equação 1.

$$
X=\frac{H_{0}-H}{H_{0}-H_{r e c}}
$$

Onde $\mathrm{H}_{0}$ corresponde à dureza medida após a deformação a frio, $\mathrm{H}$ rec é a dureza do material no estado inicial (no caso, superenvelhecido) e H é a dureza do material após recozimento sobre condições de tempo e temperatura determinados.

As frações amaciadas estimadas através da Equação 1 foram ajustadas ao modelo JMAK, que coloca a fração recristalizada (X) em função do tempo de recozimento a uma dada temperatura (t) de acordo com a Equação (2).

$$
X=1-\exp \left(-A t^{n}\right)
$$

Onde $A$ e $n$ são constantes a ser determinadas experimentalmente por meio da linearização da Equação (2).

Os dados obtidos por ambos os tratamentos isotérmicos foram ajustados ao modelo JMAK. Para esse fim, foram plotados o logaritmo natural do tempo em segundos, contra In $\{\ln [1 /(1-X)]\}$, onde $X$ é a fração amaciada ou amolecida estimada com base nas medidas de dureza Vickers. Os gráficos são mostrados na Figura 9.

(a)

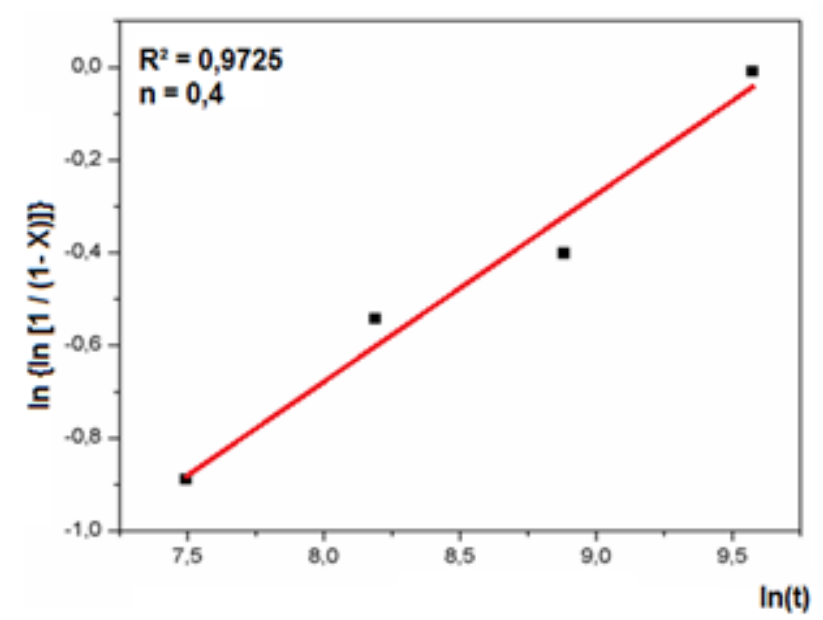

(b)

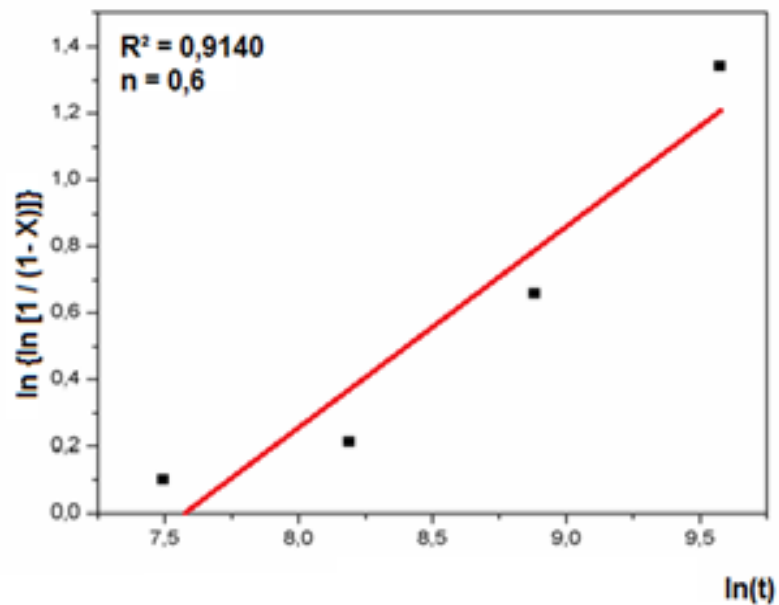

Figura 4 - Gráficos In $\{\ln [1 /(1-X)]\}$ versus In (t) para recozimentos isotérmicos a (a) $200^{\circ} \mathrm{C}$ e (b) $250^{\circ} \mathrm{C}$. 
Para o recozimento isotérmico realizado a $200^{\circ} \mathrm{C}$, os parâmetros $A$ e $n$ do modelo JMAK calculados a partir da curva apresentada na Figura $9\left(200^{\circ} \mathrm{C}\right)$ são respectivamente $2,06 \times 10^{-2}$ e 0,4 . Já para o tratamento realizado a $250^{\circ} \mathrm{C}$, os parâmetros calculados $A$ e $n$ correspondem respectivamente a $1,06 \times 10^{-2}$ e 0,6 .

Os resultados obtidos mostram que, conforme esperado, um aumento na velocidade de amolecimento com o aumento da temperatura $\left(n=0,4\right.$ para recozimento a $200^{\circ} \mathrm{C}$ e $n=0,6$ para recozimento a $250^{\circ} \mathrm{C}$ ). Segundo as curvas de recozimento isotérmico, para se obter uma fração amolecida de $50 \%$ seriam necessários cerca de 20 minutos para a amostra recozida a $250^{\circ} \mathrm{C}$ e cerca de 2 horas para a amostra recozida a $200^{\circ} \mathrm{C}$.

A Tabela 3 resume os parâmetros da cinética de amolecimento e do ajuste ao modelo JMAK, determinados para os recozimentos realizados.

Tabela 3. Parâmetros do ajuste JMAK para a Iiga AA 7075 superenvelhecida a $300^{\circ} \mathrm{C}$ por 5 horas, deformada $45 \%$ de redução em espessura por laminação e recozida isotermicamente em duas temperaturas diferentes.

\begin{tabular}{cccc}
\hline Temperatura $\left({ }^{\circ} \mathbf{C}\right)$ & $\mathbf{A}$ & $\mathbf{n}$ & Fator de correlação $\left(\mathbf{R}^{2}\right)$ \\
\hline 200 & $2,06 \times 10^{-2}$ & 0,4 & 0,9725 \\
\hline 250 & $1,06 \times 10^{-2}$ & 0,6 & 0,914 \\
\hline
\end{tabular}

A Figura 10 mostra uma micrografia obtida por microscopia óptica de luz polarizada da amostra recozida a $300^{\circ} \mathrm{C}$ por 4 horas. Aparentemente, não houve o surgimento de novos grãos, ou seja, não ocorreu recristalização, sendo a queda de dureza justificada somente por intensa recuperação. Dessa forma a boa concordância com o modelo JMAK seria apenas uma coincidência.

Outra possibilidade é que caso tenham surgido novos grãos, estes só sejam observáveis mediante com o uso de maiores aumentos, o que implicaria no uso, por exemplo, de técnicas como a difração de elétrons retroespalhados (EBSD; Electron Back Scatter Diffraction).

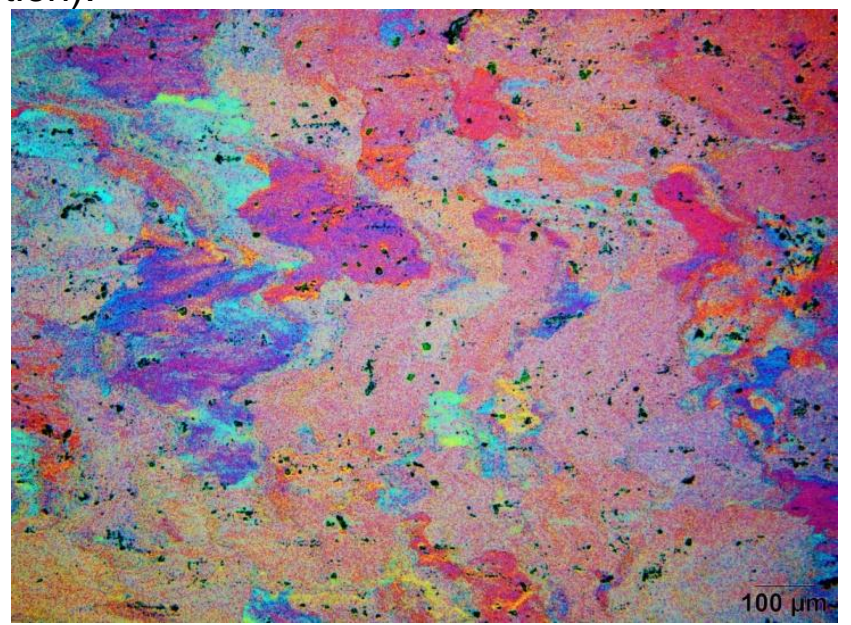

Figura 5 - Micrografia obtida com auxílio de microscopia óptica de luz polarizada da amostra laminada a frio e recozida a $300^{\circ} \mathrm{C}$ por 4 horas.

A continuidade do presente trabalho será direcionada para obter evidências conclusivas que apontem para a ocorrência ou a não ocorrência de recristalização, visto que os resultados obtidos com auxílio de microscopia óptica de luz polarizada até esse momento foram neste aspecto inconclusivos. A técnica de EBSD poderá ser utilizada, já que essa técnica permite a análise da estrutura de grãos muito 
menores, além de possibilitar a determinação da diferença de orientação entre grãos e subgrãos (mesotextura).

\section{CONCLUSÕES}

Amostras da liga AA 7075 na condição T6 foram caracterizadas e submetidas a tratamento térmico de superenvelhecimento. Após tratamento a $300^{\circ} \mathrm{C}$ por 5 horas, observou-se por microscopia eletrônica de varredura a formação de precipitados finos em contornos de grão. A detecção dessas partículas ( $\left.M g Z n_{2}\right)$ foi possível com auxílio de difração de raios $X$. A amostra superenvelhecida apresentou significativa queda de dureza Vickers em comparação com o estado T6; 82 HV após superenvelhecimento, contra $180 \mathrm{HV}$ para a amostra no estado T6.

A redução de $45 \%$ em espessura por laminação na temperatura ambiente causou significativo endurecimento. A dureza Vickers passou de 82 no estado superenvelhecido para 118 após a deformação.

Os recozimentos isócronos de 4 horas mostraram que a dureza das amostras deformadas foi pouco afetada por recozimentos em temperaturas menores que $150^{\circ} \mathrm{C}$. Os recozimentos isotérmicos realizados a $200^{\circ} \mathrm{C}$ e $250^{\circ} \mathrm{C}$ causaram significativo amolecimento e as curvas de amolecimento em função do tempo puderam ser descritas pela equação JMAK. Para a temperatura de $200^{\circ} \mathrm{C}$, a equação encontrada para a fração amaciada foi $X=1-\exp \left(-2,06 \times 10^{-2} \cdot t^{0,4}\right)$, enquanto para a temperatura de $250^{\circ} \mathrm{C}$ a equação encontrada foi $X=1-\exp (-1,06$ $\left.\mathrm{x} 10^{-2} \cdot \mathrm{t}^{0,6}\right)$.

Embora os valores experimentais de fração amaciada apresentem boa concordância com o modelo JMAK, micrografias das amostras recozidas a $300^{\circ} \mathrm{C}$ não apresentaram evidências da ocorrência da recristalização. É possível que: i) os novos grãos formados sejam pequenos e não visíveis pelas ampliações da microscopia óptica ou; ii) só tenha ocorrido intensa recuperação nas condições estudadas e, dessa maneira, o bom ajuste ao modelo JMAK tenha sido apenas uma coincidência. Experiências em andamento utilizando EBSD poderão esclarecer esta dúvida sobre a ocorrência ou não de recristalização.

\section{Agradecimentos}

Os autores agradecem à CAPES pelo apoio financeiro recebido através da bolsa de mestrado concedida a um dos autores (Souza S.H.), à Companhia Brasileira de Alumínio (CBA) e aos seus técnicos Miguel Borodiak e Viviane Serrão pela ajuda na preparação metalográfica das amostras, ao Departamento de Engenharia de Minas e Petróleo e ao técnico Jorge Sakamoto do Laboratório de Mecânica de Rochas pela ajuda no corte de amostras com jato de água ("jet-cutting") e ao Departamento de Engenharia Metalúrgica e de Materiais da Escola Politécnica e seus servidores técnicos e administrativos pela ajuda e infraestrutura fornecidas durante a realização deste trabalho.

\section{REFERÊNCIAS}


El-Baradie ZM, El-Sayed M. Effect of double thermomechanical treatments on the properties of AA 7075 Al alloy. Journal of Materials Processing Technology.1996; 62: 76-80.

2 Viana F, Pinto AMP, Santos HMC, Lopes AB. Retrogression and re-aging of 7075 aluminium alloy: microstructural characterization. Journal of Materials Processing Technology.1999; 92-93: 54-59.

3 Wert JA, Paton NE, Hamilton CH, Mahoney W. Grain refinement in 7075 aluminum by thermomechanical processing. Metallurgical Transactions A.1981; 12(7): 1267-1276.

4 Tajally M, Huda Z. Recrystallization kinetics for aluminum alloy 7075. Metal science and heat treatment. 2011; 53(5-6): 213-217.

5 Guimarães PB, Oliveira CAN, da Silva RJF, Yadava YP, Ferreira RAS. A cinética de recristalização da liga de alumínio AA 8023. Revista Eletrônica de Materiais e Processos. 2011; 6(3).

6 Cavalcante, FF. Comportamento mecânico e tenacidade à fratura de ligas de alumínio 2024 e 7075 submetidas a diferentes tempos de envelhecimento [Dissertação de Mestrado]. Rio Grande do Norte: Universidade Federal do Rio Grande do Norte; 2016.

7 Goloborodko A, Ito T, Yun X, Motohashi Y, Itoh G. Friction stir welding of a commercial 7075-T6 aluminum alloy: grain refinement, thermal stability and tensile properties. Materials Transactions. 2004; 45(8): 2503-2508.

8 Cogan SF, Gayle FW, Klein JD, Cocks FH, Shepard ML. Extraction and X-ray analysis of phases in aluminium alloys. Journal of Materials Science. 1978: 13(12): 2687-2691.

9 Wert, J. A. Identification of precipitates in $7075 \mathrm{Al}$ after high-temperature aging. Scripta Metallurgica. 1981: 15(4): 445-447

10 Triveño C, de Lima RL. Avaliação da liga 7075-T651 fundida em molde de areia. ABCM - Congresso Nacional de Engenharia Mecânica. 2010

11 Deaquino-Lara R, Gutiérrez-Castañeda E, Estrada-Guel I, Hinojosa-Ruiz, G., GarcíaSánchez E, Herrera-Ramírez, JM, et al. Structural characterization of aluminium alloy 7075-graphite composites fabricated by mechanical alloying and hot extrusion. Materials \& Design.2014; 53: 1104-1111. 